\title{
Scanning electron microscope cathodoluminescence imaging of subgrain boundaries, twins and planar deformation features in quartz
}

\author{
M. F. Hamers ${ }^{1}$ - G. M. Pennock ${ }^{1}$ - M. R. Drury ${ }^{1}$
}

Received: 4 July 2016 / Accepted: 15 October 2016 / Published online: 14 November 2016

(C) The Author(s) 2016. This article is published with open access at Springerlink.com

\begin{abstract}
The study of deformation features has been of great importance to determine deformation mechanisms in quartz. Relevant microstructures in both growth and deformation processes include dislocations, subgrains, subgrain boundaries, Brazil and Dauphiné twins and planar deformation features (PDFs). Dislocations and twin boundaries are most commonly imaged using a transmission electron microscope (TEM), because these cannot directly be observed using light microscopy, in contrast to PDFs. Here, we show that red-filtered cathodoluminescence imaging in a scanning electron microscope (SEM) is a useful method to visualise subgrain boundaries, Brazil and Dauphiné twin boundaries. Because standard petrographic thin sections can be studied in the SEM, the observed structures can be directly and easily correlated to light microscopy studies. In contrast to TEM preparation methods, SEM techniques are non-destructive to the area of interest on a petrographic thin section.
\end{abstract}

Keywords Quartz · Microstructures .

Cathodoluminescence $\cdot$ Subgrain boundaries .

Twin boundaries

\section{Introduction}

Quartz is one of the main constituents of crustal rocks, and its properties are therefore very relevant to crustal deformation. Finding a reliable technique to estimate the size

\footnotetext{
M. R. Drury

m.r.drury@uu.nl

1 Department of Earth Sciences, Faculty of Geosciences, Utrecht University, Budapestlaan 4, 3584 CD Utrecht, The Netherlands
}

and density of the various elements making up deformed microstructures in quartz can provide a useful tool to help understand the processes active in natural rocks.

Microstructures in tectonically deformed quartz include dislocations, subgrains and various types of twins. Quartz subjected to shock metamorphism shows various types of structure, of which planar deformation features (PDFs) are the most widely studied and are considered conclusive shock evidence (e.g. French and Koeberl 2010). Dislocations and subgrains can be used as palaeostress indicators (Twiss 1977; White 1979; Schmid et al. 1980). Twinning occurs during both growth and deformation processes and includes Brazil and Dauphiné types. Brazil twins represent a change of hand across the twin boundary (e.g. McLaren and Phakey 1966), while Dauphiné twins are related by a $180^{\circ}$ (or apparent $60^{\circ}$ ) rotation around the $c$ axis (e.g. McLaren and Phakey 1969). PDFs are originally planes of amorphous silica, but after healing and recrystallisation of the amorphous material, they can be recognised in the transmission electron microscope (TEM) as planes of high dislocation density (e.g. Goltrant et al. 1992; Trepmann and Spray 2006). Recently, Dauphiné twins have received some interest in relation to shock effects in quartz (Chen et al. 2011; Trepmann and Spray 2005; Wenk et al. 2005, 2011), and basal Brazil twins are considered as diagnostic shock evidence (Goltrant et al. 1991, 1992; Leroux and Doukhan 1996; Leroux et al. 1994; Trepmann 2008; Trepmann and Spray 2006).

A wide range of observation techniques have been used to study deformation microstructures in quartz. Each technique has benefits and limitations when making a reliable estimate of the density and distribution of heterogeneously distributed microstructures. For instance, light microscopy (LM) is restricted to features greater than about a micron in size, whereas TEM is excellent for studying all 
microstructures, although the method is time-consuming, destructive and limited to tiny samples. Twins are generally not visible using LM (e.g. Spry et al. 1969), whereas electron backscattered diffraction (EBSD) and forescatter electron (FSE) imaging in the SEM are useful for showing most subgrains (Prior et al. 1996) and Dauphiné twins (e.g. Lloyd 2000; Neumann 2000). Dislocations and Brazil twins (Olesen and Schmidt 1990), on the other hand, are not routinely observed. Cathodoluminescence (CL) is good for examining defects arising from differences in impurities associated with growth zones (Götze et al. 1999, 2001; Götze 2009) and deformation microstructures, such as fractures, deformation lamellae, PDFs and mechanical Brazil twins found in shocked quartz (Seyedolali et al. 1997; Boggs et al. 2001; Cavosie et al. 2010; Hamers and Drury 2011; Hamers 2013; Hamers et al. 2016). In particular, composite colour CL imaging in the scanning electron microscope (SEM), in which red, green and blue filters are used, is useful in distinguishing two types of PDFs, a nonluminescent type and a red to infrared CL type (Hamers and Drury 2011; Hamers et al. 2016). A one-to-one correlation of SEM-CL and TEM showed that the non-luminescent shock features were amorphous PDFs, whereas the red CL type was healed PDFs or shock induced Brazil twins (Hamers et al. 2016). Tectonic deformation lamellae show red to blue CL (Hamers and Drury 2011).

In this paper, we examine a range of quartz samples using composite colour SEM-CL, EBSD, FSE and TEM. The samples contain deformation and growth microstructures, including dislocations, subgrains, Dauphiné twins, Brazil twins (both shock induced and growth) and healed PDFs. By comparing SEM-CL images, EBSD maps and TEM foils taken from the same area of interest, features in the CL images were correlated directly to TEM microstructures. We show that composite colour or red-filtered SEM-CL is a very easy method for imaging and assessing subgrain and twin boundaries.

\section{Materials and methods}

Four different quartz-bearing samples or quartz crystals were studied: a tectonically deformed quartzite, sampled from the Sillimanite-K feldspar metamorphic zone at Cap de Creus, NE Spain (Fig. 3 in Druguet 2001); an undeformed single crystal of smoky quartz with Brazil twins from unknown location (sample SQ-1A); and shock deformed quartz grains from the impact structures Rochechouart (201 Ma) in France (e.g. Schmieder et al. 2010), and Vredefort (2 Ga) in South Africa (Leroux et al. 1994). The Cap de Creus quartzite (sample CML-2) is highly deformed and recrystallised, with most grains showing well developed subgrains. The Rochechouart lithic breccia sample ( $\mathrm{RO} 2$, grain 17) contains quartz grains with healed PDFs, Dauphiné twins and subgrains, while the Vredefort granite gneiss sample (sample 55, grain 3) contains quartz grains with basal Brazil twin type PDFs, Dauphiné twins and subgrains (Hamers 2013; Hamers et al. 2016).

Samples were polished to a $1 \mu \mathrm{m}$ finish with $\mathrm{Al}_{2} \mathrm{O}_{3}$, finishing with a chemical mechanical polish using colloidal silica (Syton) (Fynn and Powell 1979) for 20-60 min, to obtain a surface of sufficiently high quality for FSE imaging and EBSD mapping. A thin layer of carbon coating was applied to the samples to reduce charging and drift problems.

All microscopy investigations were carried out at the electron microscopy centre at Utrecht University. SEM$\mathrm{CL}$ images were recorded at room temperature, using electron acceleration voltages of $5-10 \mathrm{kV}$ and electron beam currents of 1.6-8.4 nA, in an FEI Nova Nanolab 600 dual beam SEM with focused ion beam (FIB) and a panchromatic Gatan PanaCL detector (Gatan UK, Oxford, UK). The PanaCL detector has a detection range of 185$850 \mathrm{~nm}$. Red (transmits red light, wavelength range 595$850 \mathrm{~nm}$ ), green (transmits green light, wavelength range 495-575 $\mathrm{nm}$ ) and blue (transmits blue light, wavelength range $185-510 \mathrm{~nm}$ ) (RGB) filters in the CL detector were used to record colour filtered images, which were combined into a colour composite RGB image using Adobe Photoshop, by including the three filtered images in the appropriate red, green or blue channel of a new image file. Because the contrast and brightness were adjusted individually for each channel before combination into the RGB image, the CL colours in these images are not quantitative (i.e. do not indicate precise specific CL emission wavelength), but indicate in which colour range the main CL emission of a feature in the sample is. See Hamers and Drury (2011) for a more detailed discussion of SEM-CL imaging.

In order to detect twinning and subgrains in the samples, FSE images and EBSD maps were made of the same area as in CL for the Cap de Creus, Vredefort and Rochechouart samples. This was done using a Philips XL30 SFEG SEM equipped with a Nordlys camera and Oxford-HKL Channel 5 software. Electron acceleration voltages between 15 and $20 \mathrm{kV}$ were used, with a nominal electron beam current of $2 \mathrm{nA}$ and a $50 \mu \mathrm{m}$ aperture. Specimen working distance was $20 \mathrm{~mm}$ with a sample tilt of $70^{\circ}$. Step sizes (i.e. the distance between two point measurements) of 0.2 and $0.5 \mu \mathrm{m}$ were used, and EBSD patterns were collected with rates between 5 and $30 \mathrm{~ms}$; successful indexing rates were typically above 95\%. EBSD map Fig. 1 was processed using an orientation averaging filter (Humphreys et al. 2001), to improve angular resolution so that low-angle misorientations measured between pixels were resolved in the microstructures (Pennock et al. 2002; Brough et al. 2006). 

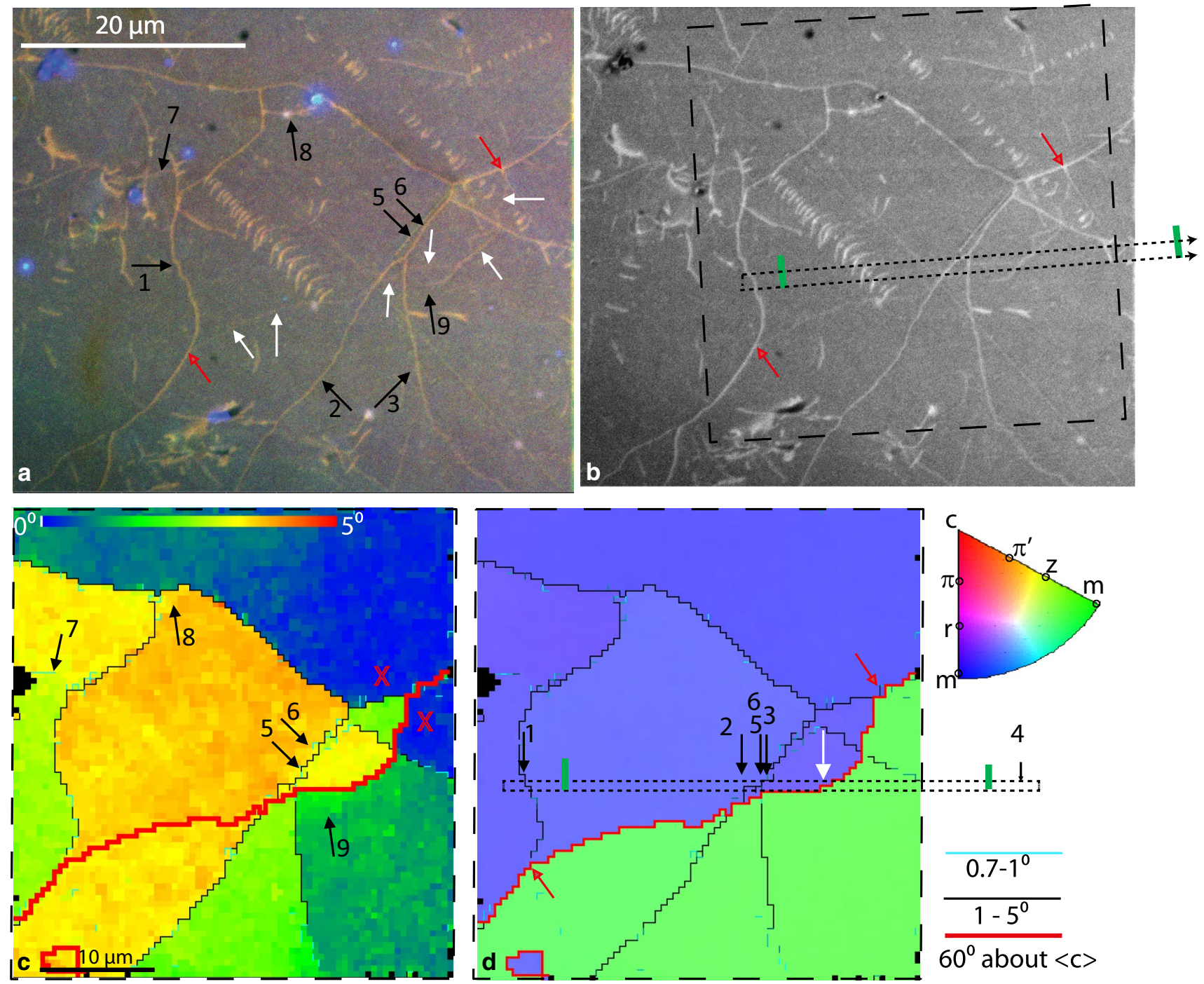

\section{4}

Fig. 1 Comparison of SEM-CL and EBSD microstructures in deformed quartzite from Cap de Creus. a Red-green-blue (RGB) composite colour SEM-CL image, b red-filtered SEM-CL image, $\mathbf{c}$ EBSD relative texture image or (mis)orientation, from a given pixel, is used to show small changes in (mis)orientation in a microstructure: as a Dauphiné twin (equivalent to a rotation of $60^{\circ}$ about the $c$ axis, [0001]) cuts across the microstructure, small changes in (mis)orientation are not highlighted for the complete microstructure in the image if only one reference pixel is used. A relative (mis)orientation from two pixels is therefore used, selected from either side of the Dauphiné twin, with a deviation of $0^{\circ}(\mathrm{red})$ to $5^{\circ}$ (blue); higher deviations are

To be able to link features in the CL images and EBSD maps directly to microstructure, TEM analysis was carried out on thin sections taken from the same sample area studied in CL images and EBSD maps. TEM sections, with a thickness of $\sim 100-200 \mathrm{~nm}$, were prepared in the FEI Nova Nanolab instrument, using a focused gallium ion beam (FIB) and a standard lift-out procedure (Wirth 2009) giving precise selection of the TEM sample location. An acceleration voltage of $30 \mathrm{kV}$ was used and beam currents ranging not coloured. The regions in the centre of the image have a similar colour as both regions have a similar relative (mis)orientation to their reference pixel. d EBSD showing the orientation of crystallographic plane normals parallel to the horizontal direction in the image: the image is coloured according to the inverse pole figure shown in the legend. Black arrows indicate subgrain boundaries (labelled 1-9) and white arrows Dauphiné twin boundaries, which were identified using EBSD. Large rectangle shows the location of the EBSD images in c and d. Narrow rectangle shows approximate location of TEM foil shown in Fig. 2, which extends beyond the imaged region: green bars show the extent of the final thinned TEM section

from $20 \mathrm{nA}$ down to $0.3-0.5 \mathrm{nA}$ for the final polishing steps. The FIB-SEM preparation of the TEM foils provides a direct, often one-to-one correspondence of PDFs in TEM and SEM-CL images. For the Cap de Creus and smoky quartz samples, SEM-CL images were recorded on the thick TEM section after mounting to the TEM grid $(\sim 6 \mathrm{nA}$ finish with the gallium ion beam and $0^{\circ}$ stage tilt angle) and before final thinning of the section down to a thickness of about 100-200 $\mathrm{nm}$. The SEM-CL imaging enabled a 
direct correlation between the CL signal and the associated defects at TEM resolution. TEM analysis was carried out on an FEI Tecnai 20 FEG instrument, operated at $200 \mathrm{kV}$, with a double tilt holder.

\section{Results}

\section{Cap de Creus deformed quartzite}

The Cap de Creus quartzite was sampled from a zone of high D2 deformation (Druguet 2001) away from any D3 shear zones. The quartzite has a deformed and recrystallised microstructure, with most grains showing well developed subgrains in cross-polarised light. Figure 1a shows a composite colour SEM-CL image of part of a grain. The majority of the microstructures show a red cathodoluminescence (bright in the red-filtered image Fig. 1b): a few features, mainly pores, show blue luminescent and occasionally green luminescent (probably due to remains of polishing material); apart from the pores, the green filtered images (not shown) show a similar microstructure to the red luminescence but with a weaker intensity. The red luminescence (Fig. 1b) shows the clearest microstructures: a comparison with EBSD maps, shown in Fig. 1c, d, shows that the lines in red luminescent CL imaging are predominantly subgrain boundaries and Dauphiné twins. The track of arc shaped lines is a topographical feature induced by polishing and does not show in the EBSD map.

All of the subgrain boundaries shown in the EBSD relative texture image (Fig. 1c) were imaged using SEM-CL. The relative texture image (Fig. 1c) shows that the misorientations of the subgrain boundaries are predominantly between $1^{\circ}$ and $5^{\circ}$, although contrast differences in the image show that a few low-angle boundary misorientations of less than $0.7^{\circ}$ are also present. A comparison of microstructures shown by CL and EBSD in Fig. 1 shows that boundaries with misorientations greater than $0.7^{\circ}$ are identified with EBSD in these samples. Misorientations between pixels lower than $0.7^{\circ}$ occur between random pixels, rather than at actual microstructural boundaries. Therefore, misorientations less than $0.7^{\circ}$ fall into the category of noise (Pennock et al. 2002; Brough et al. 2006). However, not all of the subgrain boundaries in the CL images are resolved in terms of a misoriented boundary in the EBSD map, in particular, very-low-angle boundaries with a misorientation less than $0.7^{\circ}$. For example, subgrain boundary 7 is predominantly below the angular resolution for this EBSD map, and subgrain boundaries 8 and 9 are almost entirely below the angular resolution: these low-angle boundaries are only resolved as changes in orientation in relative texture images. In addition, the two closely spaced subgrain boundaries, 5 and 6 , are not completely resolved in the EBSD map, in part because the boundary misorientation for one boundary is low and in part because the boundary separation is of the same order as the step size.

The location of the TEM section (narrow rectangle shown in Fig. 1b, d) was placed to cross several closely spaced subgrains $(2,3,5$ and 6) and the Dauphiné twin boundary (white arrow), which cuts across the TEM section so that about half of the TEM section is on one side of the twin. Figure 1d highlights the different orientation of the $r$ (purple colour) and $z$ (green colour) planes on either side of the Dauphiné twin boundary in relation to the TEM section (colours in Fig. 1d are the same as in the inverse pole figure to the right).

An overview of the complete TEM section (with the polished surface uppermost) is shown using SEM-CL imaging (Fig. 2a) together with the corresponding TEM bright field image showing most of the same area after final thinning (Fig. 2b). The exposed FIB surface in the CL image shows the location of the Dauphiné twin (horizontal white arrow) and subgrain boundaries (horizontal black arrows) identified in the polished surface. The location of subgrain boundaries 2 and 4 in the SEM-CL of the FIB surface correlates exactly with the subgrain boundaries in the TEM section; this is seen more clearly at different tilts in the TEM image (Fig. 2c, d) which confirm that several boundaries are present between subgrains 2 and 3. One of the boundaries close to the polished surface is the Dauphiné twin, which zigzags close to the upper polished surface, before bending sharply over close to subgrain 3 (insert Fig. 3a). Although the path of subgrain 3 and the Dauphiné twin largely coincide, the dip of the twin plane into the TEM thin section is shallower than that of the subgrain boundary plane. Analysis of TEM images at several two-beam conditions showed no misorientation across the twin boundary other than the $60^{\circ}$ rotation of the Dauphiné twin and no dislocations in the inclined boundary plane, whereas subgrain boundaries did show a misorientation and contain dislocations (Fig. 3). In two-beam imaging, the crystal is tilted so that only one set of lattice planes is diffracting strongly. The contrast in a two-beam image is mainly produced by local variations in the lattice plane orientation. A low-angle subgrain boundary is also observed close to the Dauphiné twin boundary (Fig. 3a, dotted arrows). This boundary was not apparent in the EBSD images, in part because of the spatial resolution, but also because such small angle boundaries are not detected with standard EBSD mapping techniques (high-angular resolution EBSD (HR-EBSD) techniques as described by Wallis et al. (2016) could provide more detail). The zigzag pattern of the Dauphiné twin was not resolved in the CL image of the thick TEM section (Fig. 2a). Further analysis of the Dauphiné twin was hampered by interfering contrast caused by the high dislocation density in the 

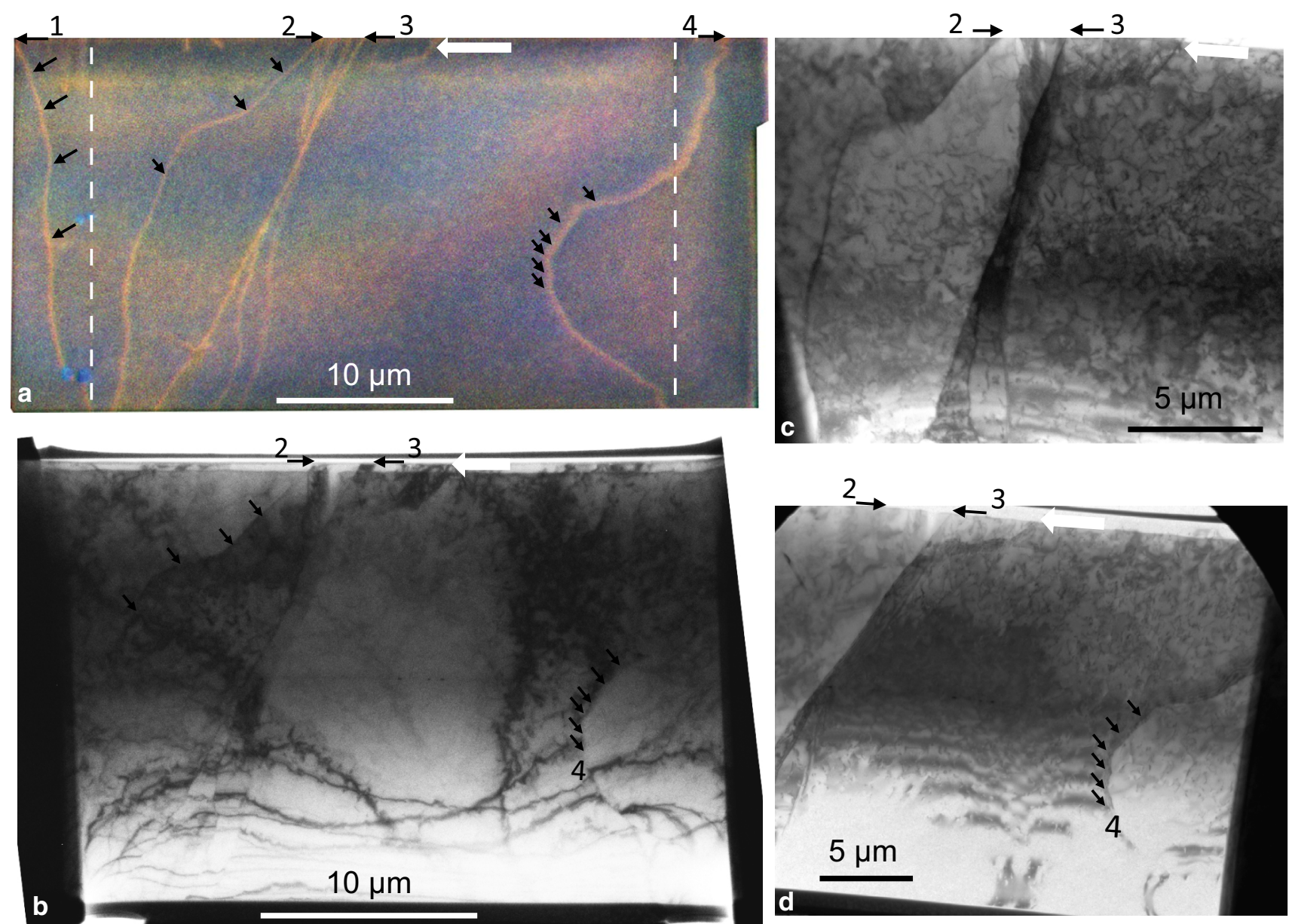

Fig. 2 Comparison of $\mathrm{CL}$ and TEM microstructures in deformed quartzite from Cap de Creus. a Composite colour SEM-CL image of the thick TEM section before final thinning to electron transparency. The extent of the thick section is shown by the narrow rectangle in Figs. 1b, d. Vertical dotted lines indicate the width of the final FIB thinned TEM section, shown in the bright field TEM image. b Features at the upper edge of the TEM section (i.e. the polished surface shown in Fig. 1) are shown by horizontal arrows: subgrain

matrix (Fig. 3), the presence of several low-angle subgrain boundaries and also by the almost uniform thickness of the thin sections, which gave only weak thickness fringe contrast. Nevertheless, asymmetry in weak thickness fringe patterns across the Dauphiné twin in the lower part of the section (Fig. 2c) provides additional evidence that the boundary was a Dauphiné twin (McLaren and Phakey 1969). In lower parts of the thin section, the subgrain(s) and Dauphiné twin separate and both TEM and SEM-CL images show three boundaries. Although this quartz sample contains a high dislocation density (Fig. 2c), individual dislocations are not resolved in the SEM-CL images. A slight increase in the background variation in contrast was observed after scanning in the SEM-CL image of the thick TEM section. boundaries are shown as small black arrows, and the location of the Dauphiné twin (identified in the EBSD images) is shown by a large white arrow. Black arrows in the SEM-CL and TEM images show the location of several subgrain boundaries below the polished surface. $\mathbf{c}$ TEM image showing high dislocation density in the sample. d TEM image clearly showing correlation between subgrain boundaries 3 and 4 in the SEM-CL image a

\section{Growth Brazil twins in a single crystal}

SEM-CL and TEM images of a single crystal of smoky quartz sample with growth Brazil twins are shown in Fig. 4. The SEM-CL images (Fig. 4a, b) show the twins as red luminescent straight lines in different orientations, which do not cross-cut each other. Also some features that look like free dislocations (white arrows in Fig. 4a) can be recognised in the CL images of the polished surface, which have exactly the same colour as the Brazil twins. The composite colour SEM-CL image of the TEM section before thinning (Fig. 4c) shows bright orange to reddish luminescent lines that correspond to the red/bright lines in Fig. 4a, b. The colour differences between the thin section (Fig. 4a) and the thick TEM section (Fig. 4c) can be due 

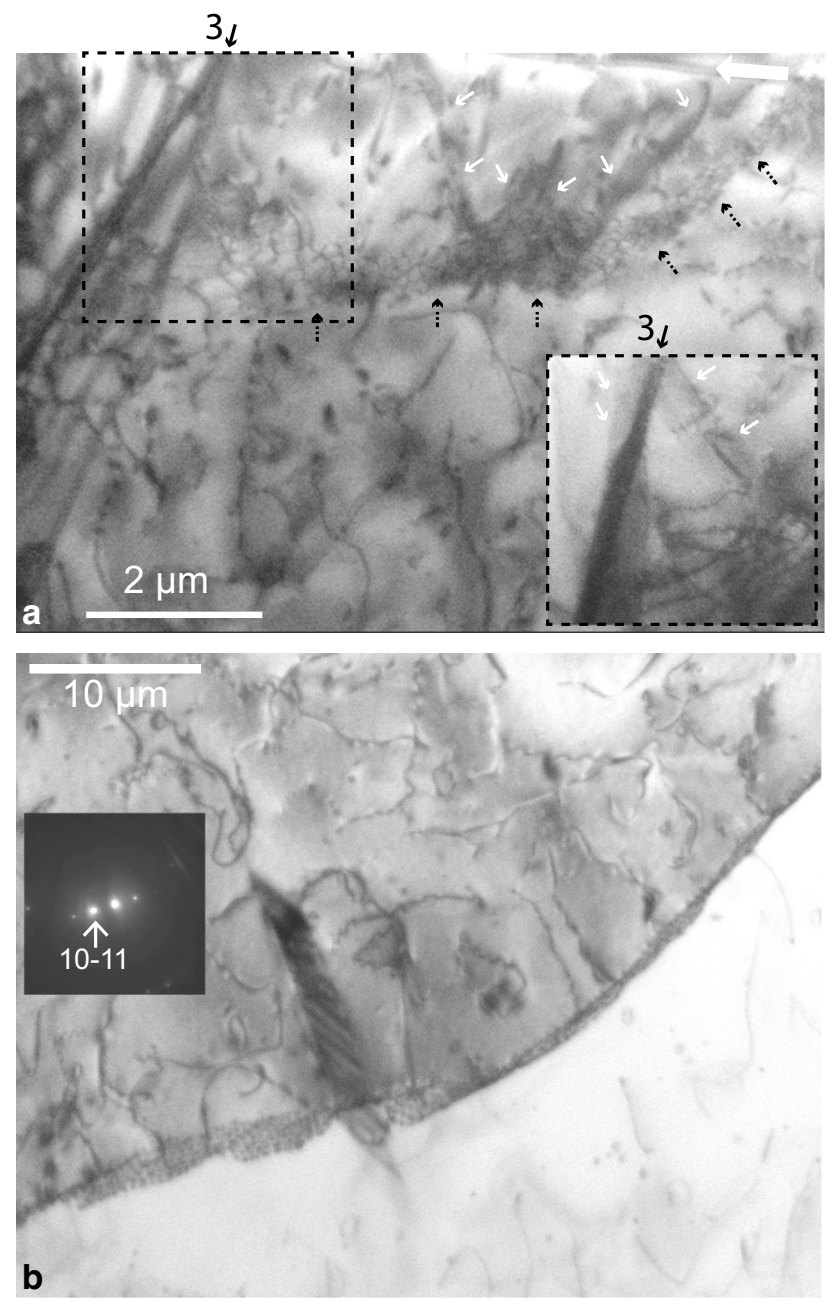

Fig. 3 TEM bright field images at different tilt angles of the Cap de Creus quartzite sample. a Bright field images showing subgrain boundary 3 (black arrow) and Dauphiné twin close to the polished surface. The Dauphiné twin boundary zigzags and bends over to coincide with subgrain 3 (small white arrows and inset). Near to the polished surface, a low-angle subgrain boundary (dotted black arrows) is in close vicinity to the Dauphiné twin. Weak fringes are visible parallel to the Dauphiné twin boundary trace associated with an inclined boundary. The twin boundary is free of dislocations. b Subgrain boundary 2 showing high density of closely spaced fringes arising from dislocations along the boundary

to individual contrast and brightness adjustments of the filtered images making up the composite colour image, or they can be the result of charging effects that were a problem when imaging the thick section. The top of the thick section is indicated in Fig. $4 \mathrm{~b}$; the thick section is perpendicular to the surface imaged in $4 \mathrm{a}, \mathrm{b}$ and not mirrored, as one could think when first looking at the images. There is a direct correlation between the bright luminescent lines in the thick section in the SEM-CL image (Fig. 4c) and Brazil twin lamellae that are parallel to the $\{10-11\}$ plane determined using TEM (Fig. 4e). As can be expected from an undeformed crystal, very few dislocations are present in this sample and none are clearly recognised in the $\mathrm{CL}$ image of the thick section (Fig. 4c). The Brazil twin plane did not contain any dislocations along the boundary.

\section{Mechanical Brazil twins in a shocked granite gneiss}

An example of mechanical basal Brazil twins in a quartz grain in a granite gneiss (Sample 55, grain 7) from the Vredefort impact structure in South Africa is shown in Fig. 5. The low magnification FSE image shows contrast associated with different orientations. Detail of the boxed region is shown in the FSE image (Fig. 5b), EBSD relative texture (Fig. 5c) and red-filtered SEM-CL (Fig. 5d). The FSE image shows good contrast for the Dauphiné twins and subgrain information shown in the EBSD map. The majority of the subgrain boundaries have very low misorientations, predominantly below $0.7^{\circ}$. The SEM-CL image shows additional bright narrow straight lines running NE-SW, which were not present in the FSE or in the EBSD maps. These bright lines were identified using TEM as Brazil twins (Fig. 3b, c in Hamers et al. 2016): the dislocation density in the Brazil twin plane varied, with parts of the twin plane decorated with dislocations and most parts free of dislocations. Dauphiné and Brazil twin boundaries mostly coincide so any differences in CL intensity are difficult to distinguish: however, one short section of Dauphiné twin boundary (white arrow in Fig. 5c, d) has weaker contrast than the Brazil twin. Subgrain boundaries have a weaker CL intensity than the Brazil twins, but nonetheless give a good CL signal. The mechanical Brazil twins show the same red luminescence behaviour as the growth Brazil twins in the smoky quartz and the subgrain and Dauphiné twin boundaries in the Cap de Creus sample.

\section{Healed planar deformation features in quartz}

Figure 6a shows the red-filtered SEM-CL image of healed PDFs in a quartz grain in a lithic breccia from the Rochechouart impact structure in France (see also Fig. 4b in Hamers and Drury 2011 for the composite colour image). The bright (red luminescent, but white in this red-filtered greyscale image), straight lines indicated by black arrows are healed PDFs, which consist of planes of very high dislocation density (e.g. Goltrant et al. 1992). The PDFs are not visible in the FSE or the EBSD images. Some bright lines in the red-filtered CL image correlate to Dauphiné twin boundaries, which are easily recognised in the FSE (Fig. 6b) and EBSD (Fig. 6c) images. Other bright lines correspond to low-angle subgrain boundaries: subgrain boundary 1 is identified in the forescatter image but subgrain boundary 2 is not. Both subgrains are barely visible in the EBSD relative texture image, subgrain 2 is particularly hard to differentiate from a gradual change in contrast that 

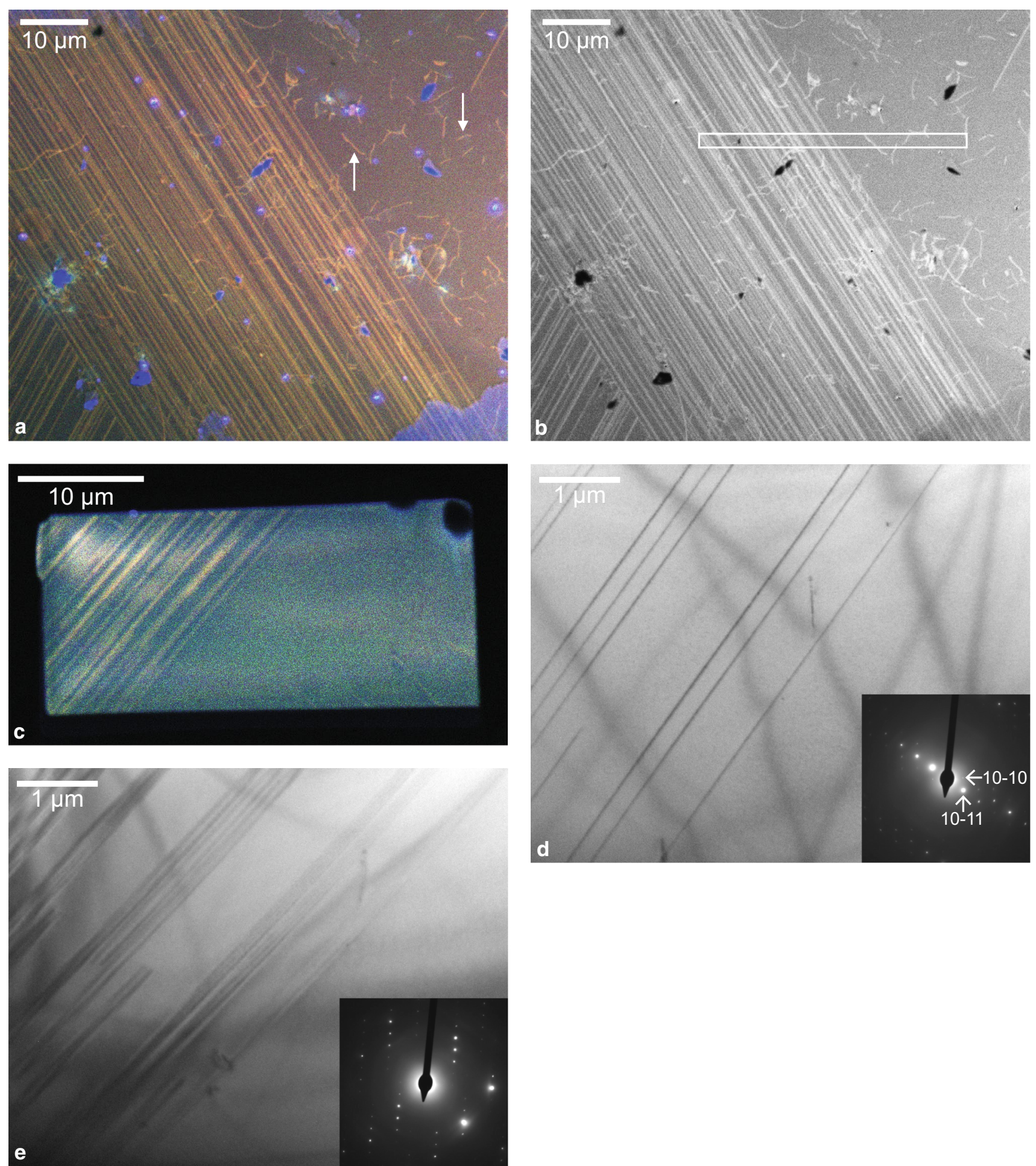

Fig. 4 Smoky quartz single crystal. a Composite colour SEM-CL image showing Brazil twins as red luminescent lines. Blue luminescent spots and areas (e.g. in the bottom right corner) are remains of the polishing material on the sample surface. Two examples of features that look like free dislocations are indicated with a white arrow. b Red-filtered SEM-CL image. White rectangle indicates location of TEM foil shown in $\mathbf{c}$ and $\mathbf{d}$. $\mathbf{c}$ Composite colour SEM-CL image of the TEM foil before thinning to the final thickness, showing Brazil

twins as red luminescent lines, while the rest of the sample appears blue in this image. d TEM bright field image and corresponding selected area diffraction pattern (SADP), showing edge on Brazil twin boundary planes parallel to $\{10-11\}$. e TEM bright field image and SADP of the same area as in d, but with the Brazil twin boundary planes in a tilted position, showing the twin planes as fringe patterns (see McLaren and Phakey 1966) rather than lines as in d 

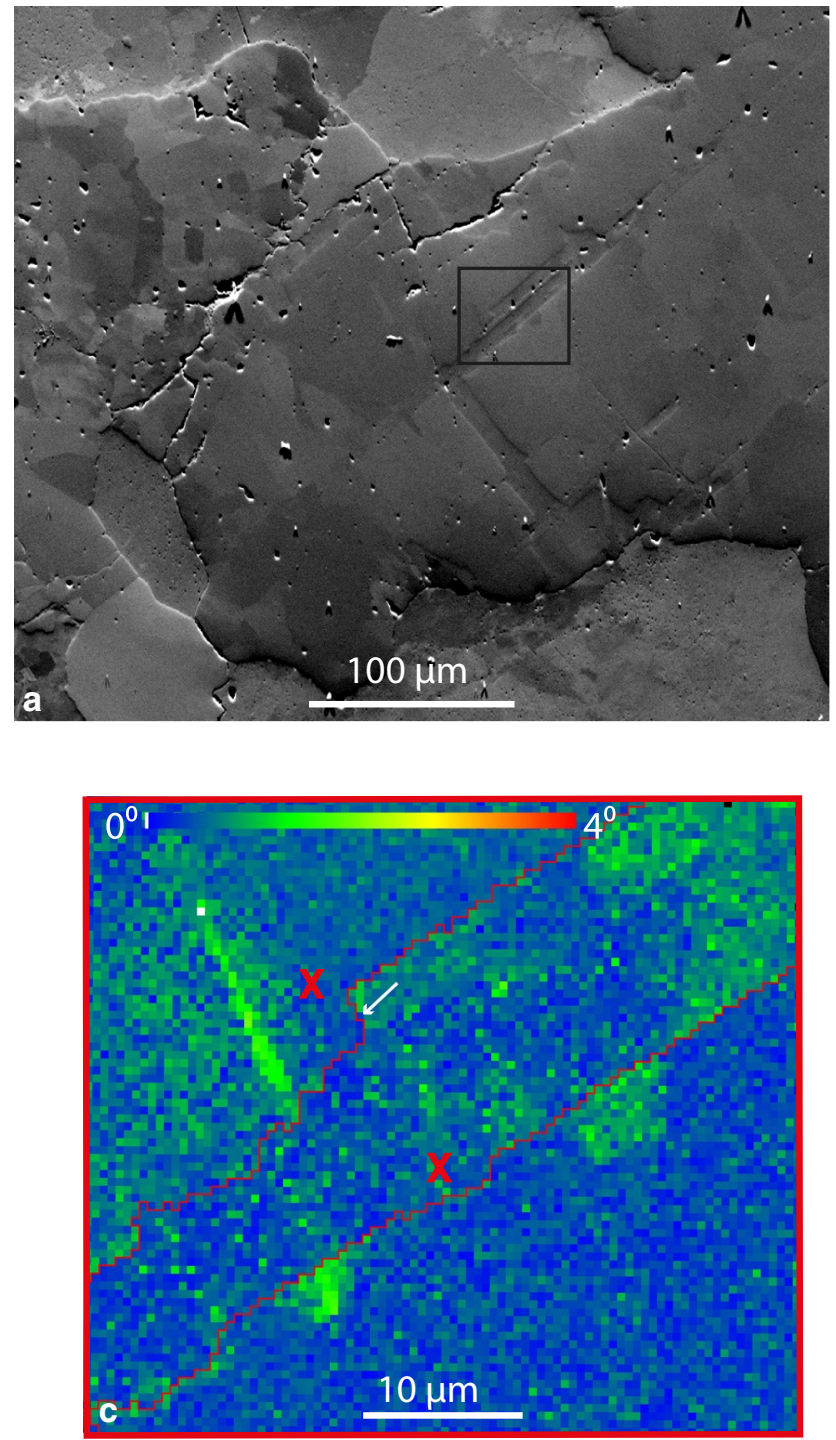

Fig. 5 a Overview FSE image of a quartz grain in shocked granite gneiss from Vredefort (sample 55, grain 7) showing contrast from different orientations in the grain. b Detailed FSE of boxed region shown in a with corresponding c EBSD map showing Dauphiné

indicates the presence of an orientation gradient. Healed PDFs, subgrain and Dauphiné twin boundaries all show about the same CL intensity.

In all of the samples described above, the red CL emission seems to increase in intensity with increased exposure to the electron beam in healed PDFs, subgrain as well as twin boundaries.

\section{Misorientation angle distributions across Dauphiné twin boundaries}

The relative misorientation angle distributions, taken across Dauphiné twin boundaries shown in Figs. 1, 5 and 6, are
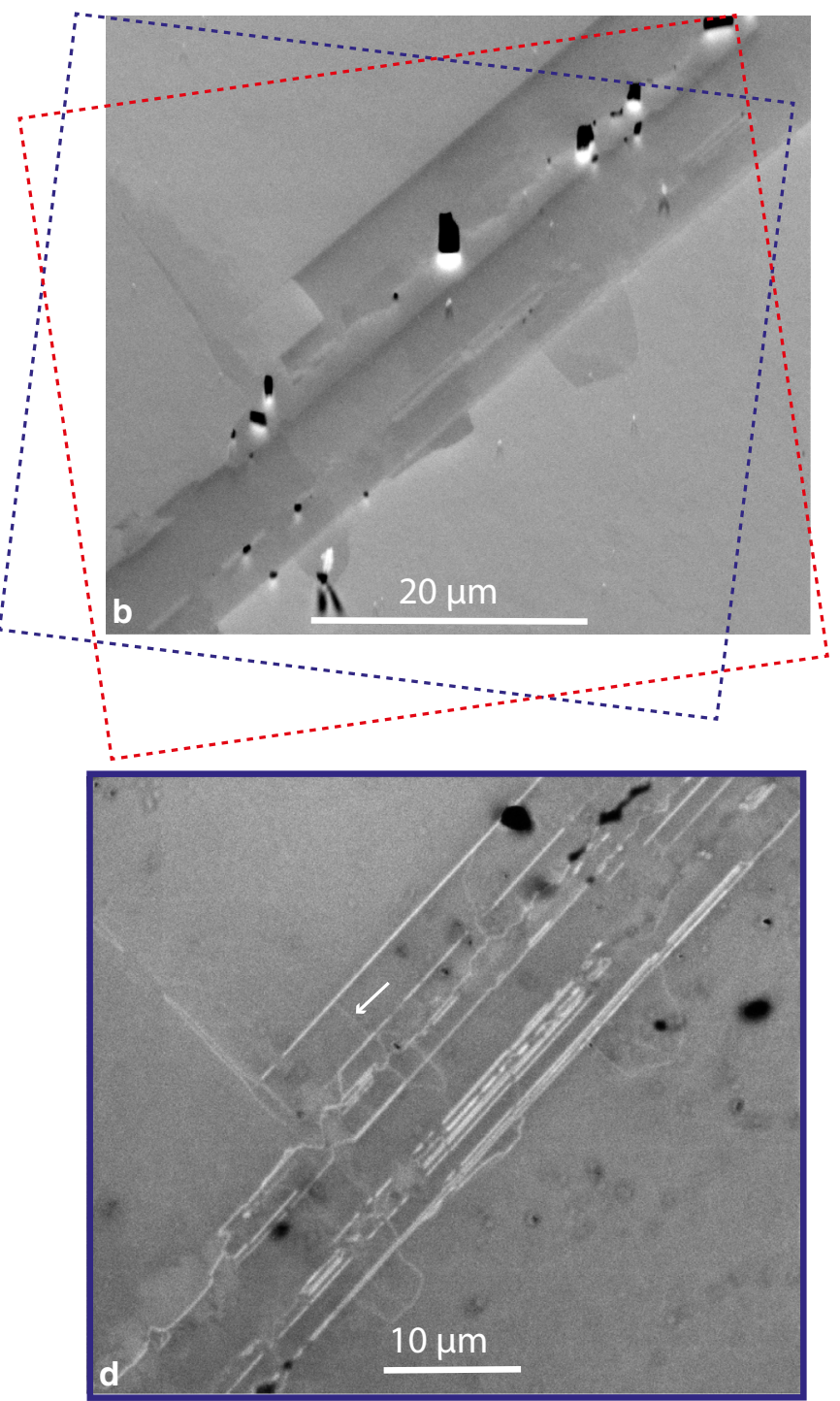

twin boundaries (red lines); colour difference (relative to the two red crosses) shows orientation differences across low-angle subgrain boundaries: d red-filtered SEM-CL image lines from subgrain, Dauphiné and Brazil twins boundaries

shown in Fig. 7. A broad range of angles (up to $15^{\circ}$ ) is generally accepted to define the twin law criterion in mapped microstructures (Brandon 1966; Palumbo et al. 1998). The misorientation angle frequency distribution across an ideal Dauphiné twin boundary, when displayed as a minimum misorientation value of $60^{\circ}$ rotation about the $c$ axis, should show a peak at $60^{\circ}$ (e.g. Lloyd 2004) although a spread of about $-0.7^{\circ}$ in misorientations is expected from the angular resolution (noise), which is the spread in misorientation found for these maps (see Fig. 1 and also Pennock et al. 2002). The misorientation distributions are biased to angles that are lower than the ideal solution, as only minimum misorientation values are plotted: the misorientation values 

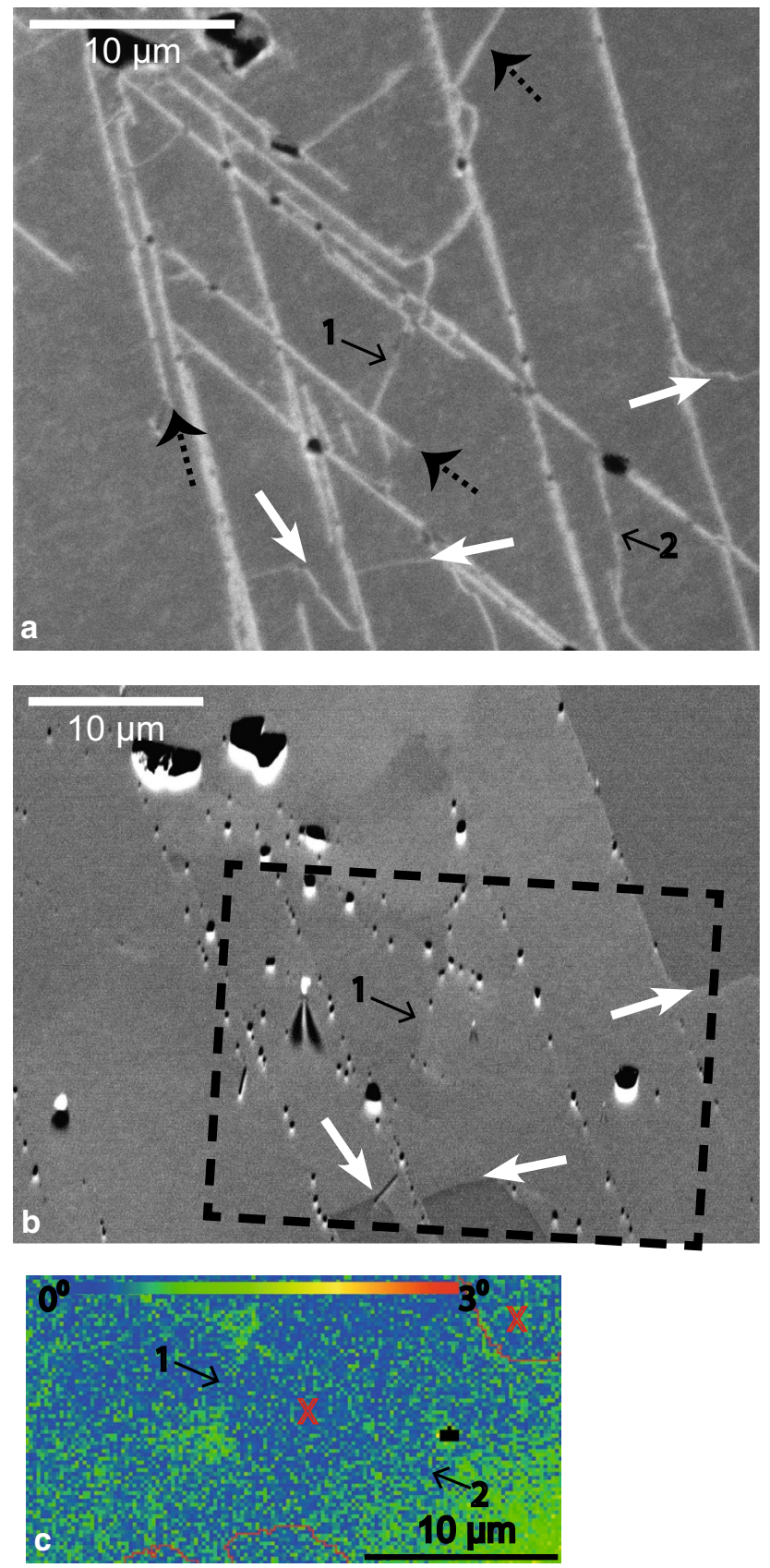

Fig. 6 Shocked quartz grain from Rochechouart with healed planar deformation features (PDFs) (black dotted arrows) and Dauphiné twin boundaries (white arrows) and subgrain boundaries (black arrows). Small holes along PDFs are fluid inclusions formed during healing of the originally amorphous material in the PDFs (see, e.g. review by Grieve et al. 1996 and references therein). a Red-filtered SEM-CL image. b Forescattered electron image; black dashed rectangle shows the location of EBSD map in $\mathbf{c}$ (aspect ratio of the EBSD map differs slightly from the boxed region because charging caused the electron beam to drift). c EBSD relative texture image of the area indicated in b showing the Dauphiné twins (red lines) and changes in orientation at subgrains are progressively reduced so that $60.1^{\circ}$ becomes a minimum misorientation of $59.9^{\circ}$ and so on, giving a modal value for an ideal Dauphiné twin in the distribution at a bin value of $59.9^{\circ}-60^{\circ}$, decreasing to $59.3^{\circ}$ because of noise in the angular measurement of the relative misorientation between pixels.

The location of the Dauphiné twin boundary (identified using EBSD, Fig. 1) shows variable brightness using SEM-CL imaging: the CL signal of the twin alone is less bright (between the red arrows, Fig. 1) than at locations where the twin and subgrain boundary coincide. The SEMCL brightness of the subgrain boundary is unaffected by the coincidence of twin boundary. Small differences from the expected ideal distribution with a modal value at $60^{\circ}$ in the misorientation distributions, measured across either the Dauphiné twin or across both the subgrain boundary and Dauphiné twin, are also apparent (Fig. 7a, b). The part of the Dauphiné twin boundary that coincides with a subgrain boundary shows a broad distribution and no peak misorientation at $60^{\circ}$, whereas the section of the Dauphiné twin boundary that does not coincide with a subgrain boundary has a distribution expected for an ideal Dauphiné twin boundary including noise. The very-low-angle boundary noted in the TEM section (Fig. 3a) falls within the angular range of noise, so is not resolved in the distribution and is also not spatially resolved. The misorientation distribution of other Dauphiné twin boundaries shown in Figs. 5 and 6 also shows an ideal misorientation angle distribution. The subgrain boundaries have low misorientation angles, $<1^{\circ}$, and the subgrain and Dauphiné twin boundary have similar SEM-CL intensity, although some parts of the Dauphiné twin appear slightly weaker.

\section{Discussion}

Correlation of images from SEM-CL with FSE, EBSD and TEM shows that red cathodoluminescence is associated with subgrain boundaries, twin boundaries and healed PDFs in quartz. Furthermore, in a well-polished surface, the red CL gives good contrast images from these microstructures thereby highlighting deformation features. Assessing densities of subgrains and twins in SEM-CL images might therefore be possible using image analysis techniques. SEM-CL is particularly effective for imaging low misorientation boundaries, which can be hard using standard EBSD mapping techniques. Although FSE techniques are also good for imaging small orientation changes, several images may be necessary to identify all of the subgrains present in a microstructure (Prior et al. 1996), which is not 
Fig. 7 Relative frequency misorientation angle distributions are shown for Dauphiné twin boundaries: distributions were made by selecting only those pixels adjacent to the boundary. All Dauphiné twin boundaries show a small deviation from the ideal rotation of $60^{\circ}$ about [0001]. a, b The Cap de Creus quartzite shown in Fig. 1 (subsets, shown in the inset, show the parts of the boundary in Fig. 1c that were selected for the subsets), $\mathbf{c}$ the Vredefort quartz grain shown in Fig. 5 and $\mathbf{d}$ the Rochechouart quartz grain shown in Fig. 6 (Raw data with no orientation averaging)

the case for SEM-CL. In addition, SEM-CL imaging can be achieved relatively easily on standard thin sections with sub-micron spatial resolution, so a one-to-one comparison with LM images is possible, making it a very useful technique. Some attention is needed to identify any topographical features that might arise from polishing, so a good polish is needed, as simulations (using software developed by Drouin et al. 2001, 2007) suggest that the CL signal originates from a maximum depth of $\sim 0.1-3.0 \mu \mathrm{m}$ under the conditions used in this study. These estimates also provide an estimation for the resolution limit of SEM-CL images, because the CL emission at any point in the sample will be an average of the CL emission of the whole interaction volume of the electron beam with the sample. Interestingly, fast ion bombardment with gallium ions used to prepare the TEM sections did not destroy the CL signal, in agreement with CL studies on diamond (De Winter et al. 2011).

Some differences in SEM-CL intensity are observed for the three microstructures studied, although differences should only be assessed within one image. Care is also needed to distinguish between differences in thickness of a line as opposed to differences in intensity of the SEMCL signal, when assessing images with the eye. Furthermore, the interaction depth of the SEM-CL signal will be sensitive to the inclination (dip) of a boundary, which is unknown in a polished surface, so the boundary dip may influence the intensity of the signal. As Dauphiné twin boundaries are not confined to a single plane, differences in dip of the twin plane are expected and may account for differences in SEM-CL intensity of the Dauphiné twin boundaries in the Rochechouart sample (Fig. 6b). Nevertheless, some images suggest that Dauphiné twin boundaries give a less intense SEM-CL signal compared to deformation Brazil twins (Vredefort shocked quartz, Fig. 5c, d). The intensity of the Dauphiné twin boundaries compared to subgrain boundaries varied, being about the same for the Vredefort sample (Fig. 5) where both subgrains and Dauphiné twin boundaries gave weaker SEM-CL compared to the Brazil twins, whereas the subgrain boundaries were generally brighter than Dauphiné twin boundaries in the tectonically deformed quartzite from Cap de Creus (Fig. 1). Making a confident distinction between Dauphiné twin boundaries and subgrain boundaries is therefore not possible based on

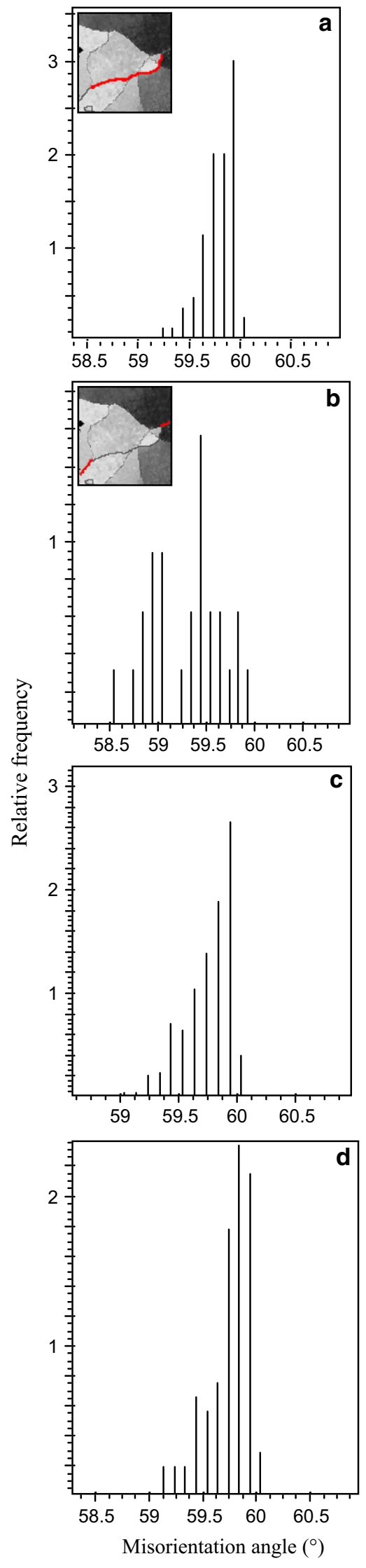


SEM-CL images alone. EBSD maps (especially HR-EBSD could be useful in this respect) or TEM analysis are always required to quantify the orientation changes and determine the nature of the boundary. Brazil twin boundaries, on the other hand, are easily distinguished from Dauphiné twin or subgrain boundaries by their characteristic straight line geometry. Some Brazil twin boundaries in CL images are thicker and brighter than others; these are probably not single twin planes, but groups of very closely spaced ones. Because of the lower spatial resolution of SEM-CL images compared to TEM bright field images, the individual structures might not always be discerned.

The misorientation angle distributions and the TEM evidence (Figs. 3a, 7a, respectively) show that the SEM-CL signal could originate from both the subgrain and from the Dauphiné twin boundaries. The two types of boundary are not spatially resolved with EBSD mapping, and verylow-angle misorientation boundaries are below the angular resolution for these EBSD maps and are therefore not distinguished from noise in the misorientation angle distributions. For the Dauphiné twin boundary shown in Fig. 1, the brighter part of the SEM-CL signal from the twin is associated with a subgrain boundary with a misorientation above the noise in the system and the weaker part of the signal was associated with a much lower angle subgrain boundary that was not detected with EBSD but was detected in TEM. We can therefore not discount that the SEM-CL for this Dauphiné twin boundary arises from dislocations in a subgrain and not from the Dauphiné twin boundary alone. For other Dauphiné twin boundaries, we cannot be sure from the misorientation angle distributions, whether or not a very-low-angle subgrain boundary is present or not; TEM is needed for this. However, TEM analysis of the Rochechouart sample (Fig. 2, Hamers et al. 2016) shows sections of Dauphiné twins exist between healed PDFs that are, indeed, free of dislocations and subgrains, so it is feasible that the SEM-CL from the Dauphiné twin indicated by the white arrow in Fig. 5c, d also arises solely from the twin boundary. Furthermore, Brazil twins, which give a strong CL signal and show no evidence of dislocations on the twin boundary (Fig. 4), suggest that twin boundaries alone can give rise to an SEM-CL signal and that dislocation density alone is not responsible for differences in SEM-CL intensity. Götze (2009) mentions that the concentration of defects and dislocations in (sub)grain boundaries in quartz results in a high CL intensity, while others associate differences in SEM-CL with differences in quartz impurity and/or point defect content in the quartz grain (e.g. Morgan et al. 2014).

Despite a good correlation between red CL in planes of high dislocation density (healed PDFs and subgrains), individual dislocations were not correlated to red CL. Although some red $\mathrm{CL}$ features in the polished surface have the appearance of dislocations (Fig. 5), many more dislocations were observed in the TEM images (Fig. 3). None of these features in SEM-CL images were directly correlated to dislocations in TEM, and therefore, we cannot be sure that they really are individual dislocations. Detailed TEM analysis and CL imaging of individual dislocations in a (S) TEM CL system could provide more information in future studies.

Subgrain boundaries, healed PDFs and twin boundaries have the same CL colour within one image. Although the colours in the SEM-CL images are not quantitative, the same colour within one image should originate from an emission with the same dominant wavelength. It can therefore be assumed that the CL emission of the various features imaged in this study has the same dominant peak in the red wavelength range of the spectrum. Unfortunately, these features proved too small-scale in practice for CL spectroscopic measurements, which could quantify the wavelength of the CL emission and identify the defect centres or impurities responsible for the dominant peaks. As mentioned above, simulations (using software developed by Drouin et al. 2001, 2007) suggest that the CL signal originates from a maximum depth of $\sim 0.1-3.0 \mu \mathrm{m}$ under the conditions used in this study. The interaction volume of the electron beam in the sample is therefore too large too only sample a twin or subgrain boundary or a single PDF. However, by looking at emission peak ratios between sample areas without PDFs and areas with a high density of PDFs, Hamers et al. (2016) measured a dominant $650-\mathrm{nm}$ emission peak in red luminescent, healed PDFs (i.e. planes of high dislocation density) from the Ries impact structure (Germany). The 650-nm emission has been confidently associated with the non-bridging oxygen hole centre (NBOHC) defect in the quartz crystal lattice (e.g. Götze et al. 2001; Stevens Kalceff 2009, and references therein). This defect can form as a result of beam damage in quartz, by dissociation of strained $\mathrm{Si}-\mathrm{O}$ bonds (Devine 1990; Stevens Kalceff and Phillips 1995). In TEM, localised electron beam damage at dislocations, Brazil twin boundaries and, to a lesser extent, Dauphiné twin boundaries are a commonly observed phenomenon and continued beam damage finally results in complete (local) amorphisation (Carter and Kohlstedt 1981; Cherns et al. 1980; McLaren et al. 1970; Comer 1972; McLaren and Phakey 1965). Similar damage caused by inelastic scattering of the incoming electrons also occurs in the SEM (Vigouroux et al. 1985, Stevens Kalceff 2009 and references therein). Beam damage and associated production of NBOHC defects at dislocations were interpreted to be the main source of the red luminescence in healed PDFs (Hamers et al. 2016). The same defect can be responsible for the red CL emission at subgrain boundaries, which also have a high dislocation density, 
and at twin boundaries. The most likely precursors for the NBOHC defect in these features are strained $\mathrm{Si}-\mathrm{O}$ bonds, since the dissociation of $\mathrm{Si}-\mathrm{O}$ bonds is associated with a 650-nm CL emission which initially increases and then stabilises (Götze et al. 2001; Stevens Kalceff 2009). Increasingly bright red CL emission with increasing scanning time and beam damage is also observed in the healed PDFs and subgrain and twin boundaries in our samples. Dislocation cores might already contain dangling bonds (non-bridging atoms), contributing to the red CL emission, but they also cause a local distortion of the crystal lattice, which could result in strained $\mathrm{Si}-\mathrm{O}$ bonds. Also in twin planes (slightly), strained bonds might be present, since the crystal structure across the twin plane is slightly distorted in both Brazil and Dauphiné twins (McLaren and Phakey 1966, 1969; Van Goethem et al. 1977).

\section{Conclusions}

Correlated SEM-CL images, FSE images, EBSD maps and TEM analysis show that subgrain boundaries and twin boundaries in quartz can be imaged using composite colour or red-filtered SEM-CL and are red luminescent in these images. The red cathodoluminescence is probably related to NBOHC defects present in dislocation cores and formed by localised electron beam damage at strained $\mathrm{Si}-\mathrm{O}$ bonds around dislocations and in twin planes. Although SEMCL imaging is not quantitative and other methods, such as EBSD and TEM analysis, are required to confirm the nature of the microstructures, the red luminescence allows a quick indication of the presence and spatial distribution of subgrain and twin boundaries in a quartz grain. The SEMCL method can be applied to standard sized petrographic thin sections, but shows features that are invisible in light microscopy, FSE and EBSD images using standard mapping techniques. This imaging technique can therefore be a useful addition to the microscopic investigation of quartzbearing rock samples.

\begin{abstract}
Acknowledgements We thank Rodger Hart for the Vredefort samples and Philippe Lambert for a great excursion around the Rochechouart impact structure. Matthijs de Winter provided invaluable support for the FIB TEM preparation work. This work was funded by the Netherlands Organisation for Scientific Research (NWO). Reviewers Geoff Lloyd and Ludovic Ferrière are gratefully acknowledged for constructive comments that have significantly improved the manuscript.
\end{abstract}

Open Access This article is distributed under the terms of the Creative Commons Attribution 4.0 International License (http://creativecommons.org/licenses/by/4.0/), which permits unrestricted use, distribution, and reproduction in any medium, provided you give appropriate credit to the original author(s) and the source, provide a link to the Creative Commons license, and indicate if changes were made.

\section{References}

Boggs S, Krinsley DH, Goles GG, Seyedolali A, Dypvik H (2001) Identification of shocked quartz by scanning cathodoluminescence imaging. Meteor Planet Sci 36(6):783-791

Brandon DG (1966) The structure of high-angle grain boundaries. Acta Metall 14:1479-1484

Brough I, Bate PS, Humphreys FJ (2006) Optimising the angular resolution of EBSD. Mater Sci Technol 22(11):1279-1286

Carter CB, Kohlstedt DL (1981) Electron irradiation damage in natural quartz grains. Phys Chem Min 7:110-116

Cavosie AJ, Quintero RR, Radovan HA, Desmond EM (2010) A record of ancient cataclysm in modern sand: shock microstructures in detrital minerals from the Vaal River, Vredefort Dome, South Africa. Geol Soc Am Bull 122:1968-1980

Chen K, Kunz M, Tamura N, Wenk H-R (2011) Evidence for high stress in quartz from the impact site of Vredefort, South Africa. Eur J Mineral 23:169-178

Cherns D, Hutchison JL, Jenkins ML, Hirsch PB, White S (1980) Electron irradiation induced vitrification at dislocations in quartz. Nature 287:314-316

Comer JJ (1972) Electron microscope study of dauphiné microtwins formed in synthetic quartz. J Cryst Growth 15:179-187

De Winter DAM, Lebbink MN, Wiggers De Vries DF, Post JA, Drury MR (2011) FIB-SEM cathodoluminescence tomography: practical and theoretical considerations. J Microsc 243(3):315-326

Devine RAB (1990) Radiation damage and the role of structure in amorphous $\mathrm{SiO}_{2}$. Nuc Instrum Methods Phys Res B Beam Inter Mater Atoms 46:244-251

Drouin D, Réal Couture A, Gauvin R, Hovington P, Horny P, Demers H (2001) Monte Carlo simulation of electron trajectory in solids. http://www.gel.usherbrooke.ca/casino/index.html

Drouin D, Couture AR, Joly D, Tastet X, Aimez V, Gauvin R (2007) CASINO V2.42 - a fast and easy-to-use modeling tool for scanning electron microscopy and microanalysis users. Scanning 29:92-101

Druguet D (2001) Development of high thermal gradients by coeval transpression and magmatism during the Variscan orogeny: insights from the Cap de Creus (Eastern Pyrenees). Tecton 332:275-293

French BM, Koeberl C (2010) The convincing identification of terrestrial meteorite impact structures: what works, what doesn't, and why. Earth Sci Rev 98:23-170

Fynn GW, Powell WJA (1979) The cutting and polishing of electrooptic materials. Adam Hilger, London, p 216

Goltrant O, Cordier P, Doukhan J-C (1991) Planar deformation features in shocked quartz; a transmission electron microscopy investigation. Earth Planet Sci Lett 106(1-4):103-115

Goltrant O, Leroux H, Doukhan J-C, Cordier P (1992) Formation mechanisms of planar deformation features in naturally shocked quartz. Phys Earth Planet Int 74:219-240

Götze J (2009) Chemistry, textures and physical properties of quartz geological interpretation and technical application. Mineral Mag 73:645-671

Götze J, Plötze M, Fuchs H, Habermann D (1999) Defect structure and luminescence behaviour of agate results of electron paramagnetic resonance (EPR) and cathodoluminescence (CL) studies. Mineral Mag 63:149

Götze J, Plötze M, Habermann D (2001) Origin, spectral characteristics and practical applications of the cathodoluminescence (CL) of quartz-a review. Mineral Petrol 71:225-250

Grieve RAF, Langenhorst F, Stöffler D (1996) Shock metamorphism of quartz in nature and experiment: II. Significance in geoscience. Meteor Planet Sci 31:6-35

Hamers MF (2013) Ph.D. thesis Identifying shock microstructures in quartz from terrestrial impacts-new scanning electron 
microscopy methods. Utrecht Studies in Earth Sciences 032, UU Dept Earth Sci, pp 191, ISBN 9789062663255

Hamers MF, Drury MR (2011) Scanning electron microscopecathodoluminescence (SEM-CL) imaging of planar deformation features and tectonic deformation lamellae in quartz. Meteorit Planet Sci 46:1814-1831

Hamers MF, Pennock GM, Herwegh M, Drury MR (2016) Distinction between amorphous and healed planar deformation features in shocked quartz using composite color scanning electron microscope cathodoluminescence (SEM-CL) imaging. Meteor Planet Sci 51:1914-1931

Humphreys FJ, Bate PS, Hurley PJ (2001) Orientation averaging of electron backscattered diffraction data. J Microsc 201:50-58

Leroux H, Doukhan J-C (1996) A transmission electron microscope study of shocked quartz from the Manson impact structure. Geol Soc Am Spec Pap 302:267-274

Leroux H, Reimold WU, Doukhan J-C (1994) A TEM investigation of shock metamorphism in quartz from the Vredefort dome, South Africa. Tecton 230:223-239

Lloyd GE (2000) Grain boundary contact effects during faulting of quartzite: an SEM/EBSD analysis. J Struct Geol 22:1675-1693

Lloyd GE (2004) Microstructural evolution in a mylonitic quartz simple shear zone: the significant roles of dauphine twinning and misorientation. In: Alsop GL, Holdsworth RE, McCaffrey KJW, Hand M (eds) Flow processes in faults and shear zones, vol 224, pp 39-61. Geol Soc London, SP

McLaren A, Phakey PP (1965) A transmission electron microscope study of amethyst and citrine. Aust J Phys 18:135-141

McLaren AC, Phakey PP (1966) Electron microscope study of Brazil twin boundaries in amethyst quartz. Phys Stat Sol 13:413-422

McLaren AC, Phakey PP (1969) Diffraction contrast from Dauphiné twin boundaries in quartz. Phys Stat Sol 31:723-737

McLaren AC, Turner RG, Boland JN, Hobbs BE (1970) Dislocation structure of the deformation lamellae in synthetic quartz; a study by electron and optical microscopy. Contrib Mineral Petrol 29:104-115

Morgan DJ, Jollands MC, Lloyd GE, Banks DA (2014) Using titanium in quartz geothermometry and geospeedometry to recover temperatures in the aureole of the ballachulish igneous complex, NW-Scotland. In: Llana-Fu'nez S, Marcos A, Bastida F (eds) Deformation structures and processes within the continental crust, vol 394, pp 145-165. Geol Soc London SP

Neumann B (2000) Texture development of recrystallised quartz polycrystals unravelled by orientation and misorientation characteristics. J Struct Geol 22:1695-1711

Olesen NØ, Schmidt N-H (1990) The SEM/ECP technique applied on twinned quartz crystals. Geol Soc Lond SP 54:369-373

Palumbo G, Aust KT, Lehockey EM, Erb U, Lin P (1998) On a more restrictive geometric criterion for "special" CSL grain boundaries. Scr Mater 38(11):1685-1690

Pennock GM, Drury MR, Trimby PW, Spiers CJ (2002) Misorientation distributions in hot deformed $\mathrm{NaCl}$ using electron backscattered diffraction. J Microsc 205(3):285-294

Prior DJ, Trimby PW, Weber UD, Dingley DJ (1996) Orientation contrast imaging of microstructures in rocks using forescatter detectors in the scanning electron microscope. Mineral Mag 60:859-869
Schmid SM, Paterson MS, Boland JN (1980) High temperature flow and dynamic recrystallisation in carrara marble. Tectonophysics 65(3-4):245-280

Schmieder M, Buchner E, Schwarz WH, Trieloff M, Lambert P (2010) A Rhaetian 40Ar/39Ar age for the Rochechouart impact structure (France) and implications for the latest Triassic sedimentary record. Meteorit Planet Sci 45(8):1225-1242

Seyedolali A, Krinsley DH, Boggs S, Ohara PF, Dypvik H, Goles GG (1997) Provenance interpretation of quartz by scanning electron microscope-cathodoluminescence fabric analysis. Geology 25:787-790

Spry A, Turner RG, Tobin RC (1969) Optical phenomena associated with Brazil twin boundaries in quartz. Am Mineral 54:117-132

Stevens Kalceff MA (2009) Cathodoluminescence microcharacterization of point defects in $\alpha$-quartz. Mineral Mag 73:585-605

Stevens Kalceff MA, Phillips MR (1995) Cathodoluminescence microcharacterization of the defect structure of quartz. Phys Rev B 52:3122-3135

Trepmann CA (2008) Shock effects in quartz: compression versus shear deformation - an example from the Rochechouart impact structure, France. Earth Planet Sci Lett 267(1-2):322-332

Trepmann CA, Spray JG (2005) Planar microstructures and Dauphiné twins in shocked quartz from the Charlevoix impact structure, Canada. Geol Soc Am Spec Pap 384:315-328

Trepmann CA, Spray JG (2006) Shock-induced crystal-plastic deformation and post-shock annealing of quartz: microstructural evidence from crystalline target rocks of the Charlevoix impact structure, Canada. Eur J Mineral 18:161-173

Twiss RJ (1977) Theory and applicability of a recrystallized grain size paleopiezometer. In: Wyss M (ed) Stress in the earth. Birkhäuser, Basel, pp 227-244

Van Goethem L, Van Landuyt J, Amelinckx S (1977) The $\alpha \rightarrow \beta$ transition in amethyst quartz as studied by electron microscopy and diffraction. The interaction of Dauphiné with Brazil twins. Phys Stat Sol 41:129-137

Vigouroux JP, Duraud JP, Le Moel A, Le Gressus C, Griscom DL (1985) Electron trapping in amorphous $\mathrm{SiO}_{2}$ studied by charge buildup under electron bombardment. J Appl Phys 57:5139-5144

Wallis D, Hansen LN, Ben Britton T, Wilkinson AJ (2016) Geometrically necessary dislocation densities in olivine obtained using high-angular resolution electron backscatter diffraction. Ultramicroscopy 168:34-45

Wenk HR, Lonardelli I, Vogel SC, Tullis J (2005) Dauphiné twinning as evidence for an impact origin of preferred orientation in quartzite: an example from Vredefort, South Africa. Geol 33(4):273-276

Wenk H-R, Janssen C, Kenkmann T, Dresen G (2011) Mechanical twinning in quartz: shock experiments, impact, pseudotachylites and fault breccias. Tectonophysics 510(1-2):69-79

White S (1979) Grain and sub-grain size variations across a mylonite zone. Contrib Mineral Petrol 70(2):193-202

Wirth R (2009) Focused ion beam (FIB) combined with SEM and TEM: advanced analytical tools for studies of chemical composition, microstructure and crystal structure in geomaterials on a nanometre scale. Chem Geol 261:217-229 